\title{
ALCOOLISMO NA ADOLESCÊNCIA: UMA ABORDAGEM EDUCATIVA PARA JOVENS NA ZONA RURAL DE CAMPOS SALES, CEARÁ
}

\section{CRUZ, Rachel de Sá Barreto Luna Callou*; SILVA FILHO, Alexandre de Souza; SAMPAIO, Karla Jimena de Araújo Jesus}

Faculdade Leão Sampaio - Juazeiro do Norte (CE), Brasil. Universidade Regional do Cariri - Crato (CE), Brasil. Instituto de Medicina Integral - Recife (PE), Brasil.

Recebido em: 18/01/2015; Aceito: 22/04/2015; Publicado: 25/08/2015

\begin{abstract}
RESUMO
A presente proposta é uma iniciativa do projeto de extensão denominado Núcleo de Intervenção em Processo de Ensino em Saúde (NIPEAS) desenvolvido com os acadêmicos do oitavo semestre do curso de Enfermagem, matriculados na disciplina "Processo Ensino-Aprendizagem em Saúde" da Faculdade Leão Sampaio. A realização desse trabalho se deu pela observação da tendência ao consumo de bebidas alcoólicas por jovens da zona rural da cidade de Campos Sales, Ceará. Objetivou-se conscientizar os jovens quanto aos riscos que o consumo exagerado e/ou precoce do álcool pode trazer à saúde, a partir de palestras educativas e dinâmicas de grupo com adolescentes de escolas municipais. A carência dos estudantes por estratégias mais carismáticas de ensino foi a primeira das várias observações realizadas. A desinformação dos adolescentes revela a inexistência efetiva de estratégias de conscientização nas escolas e a possível falência educacional do papel da família nesse aspecto. Acredita-se que a intervenção foi capaz de proporcionar mais discernimento e capacidade de escolha, algo, embora desejado, raro entre os jovens.
\end{abstract}

Palavras-chave: Alcoolismo, Adolescentes, Educação em Saúde.

\begin{abstract}
This proposal is an extension of the project initiative called Intervention Center for Health Education Process (NIPEAS) developed with the students of the eighth semester of the nursing program, enrolled in the course "Teaching-Learning Process in Health" of the Faculty Leão Sampaio. The realization of this work was made by observing the tendency to consumption of alcohol by young people in the rural town of Campos Sales, Ceará. The objective was to educate young people about the risks that the excessive consumption and /or early alcohol can bring health, from educational lectures and dynamic group with adolescents from public schools. The lack of students for more charismatic teaching strategies was the first of several observations. The lack of teenagers reveals the effective lack of awareness strategies in schools and the possible failure of the educational role of families in this regard. It is believed that the intervention was able to provide more insight and choice, something, though desired, rare among young people.
\end{abstract}

Keywords: Alcoholism, Teens, Health Education.

*Rachel de Sá Barreto Luna Callou Cruz - Instituto de Medicina Integral Prof. Fernando Figueira

Rua Esperanto, n³11, Edf. Morada Alencar, Apto 401, CEP: 50070-390, Recife-PE-Brasil

Telefone: (88) 8836-7216; (81) 9827-6567; E-mail: rachel.callou@ hotmail.com 


\section{INTRODUÇÃO}

O consumo excessivo de bebidas alcoólicas é um relevante problema de saúde pública, influenciando a morbimortalidade. A Organização Mundial da Saúde (OMS) estima que ocorram cerca de 770 mil mortes no mundo por ano (1,5\% do total de óbitos) em decorrência do uso do álcool $^{(1)}$. Evidências relacionam consumo abusivo do álcool aos acidentes de trabalho, episódios de violência e acidentes de trânsito ${ }^{(2)}$.

O álcool é conhecidamente maléfico para a saúde humana, e são os jovens os mais vulneráveis a essa tentação por ainda estarem em processo de formação de sua identidade ${ }^{(3)}$. Muitas vezes são levados por modas, ou simplesmente, curiosidades, arriscam-se a esperimentar da “diversão melhorada" de custo-benefício incerto ${ }^{(4)}$.

O consumo precoce é inversamente proporcional aos danos causados ao cérebro, devido a agressão do álcool. O pesquisador americano Aaron White, anunciou que existe um "sentido de urgência" em investigar os danos do consumo do álcool na adolescência ${ }^{(5)}$.

As pesquisas são unânimes em afirmar que o consumo exagerado do álcool na juventude afeta principalmente habilidades cognitivas, como memória e aprendizado. A explicação decorre dos danos causados ao hipocompo (região do cérebro relacionada com a memória), cujo desenvolvimento mais acentuado ocorre a partir do fim da adolecência $^{(6)}$. As pesquisas revelam também que adolescentes de 15 a 16 anos que haviam se embreagado pelo menos 100 vezes na vida se saíram pior em testes de memória do que seus equivalentes sóbrios ${ }^{(7)}$.

O alcoolismo é um problema grave de saúde pública no Brasil atingindo cerca de $10 \%$ do total da população ${ }^{(4,8)}$ e em número alarmante de $500 \%$ em alguns países nas últimas décadas ${ }^{(9)}$.

Um percentual de $12 \%$ da população acima de 12 anos desenvolve transtornos relacionados ao consumo de álcool e outras drogas, porém é a bebida a mais impactante, podendo ser responsável por até dez vezes mais agravos do que o do conjunto de drogas não socialmente aceitas ${ }^{(10)}$.

$\mathrm{Na}$ zona ruaral da cidade de Campos Sales, Ceará, esse fenômeno cresente do consumo pode ser abrangentemente observado, sendo essa uma região cuja amostra populacional é fiel ao que as pesquisas apontam como tendência.

Estando estes adolescentes sujeitos aos prejuízos que o consumo do álcool pode lhes trazer, principalmente se realizado de forma precoce, é justificada então a realização de uma intervenção direta por métodos conscientizadores afim de mudar as perspectivas de saúde da população local.

Nesse sentido, objetivou-se realizar um relato de experiência sobre as atividades educativas realizadas com jovens residentes do município em questão no intuito de esclarecer e conscientizar sobre os prejuízos quanto ao uso abusivo do álcool.

\section{METODOLOGIA}

A presente proposta é uma iniciativa do projeto de extensão denominado Núcleo de Intervenção em Processo de Ensino em Saúde (NIPEAS) desenvolvido com os acadêmicos do oitavo semestre do curso de Enfermagem, matriculados na disciplina "Processo EnsinoAprendizagem em Saúde" da Faculdade Leão Sampaio.

O NIPEAS estuda o processo de ensino e aprendizagem, em suas diversas perspectivas conceituais e aplicações; bem como desenvolve e divulga técnicas de ensino e estudos dos fenômenos e processos relativos ao ensino aprendizagem, tanto do ponto de vista teórico-conceitual quando instrumental e aplicativo.

Através de parcerias com instituições prestadoras de serviços de saúde e de educação e empresas públicas e /ou privadas procura, em suas atividades de extensão, envolver os alunos e demais 
interessados, no intuito de desenvolver novos conhecimentos, métodos e instrumentos educacionais.

Esse trabalho trata-se de uma pesquisaação. É um tipo de pesquisa onde há, de fato, uma ação por parte do pesquisador a partir de uma perspectiva de um problema coletivo ${ }^{(11,12)}$.

As intervensões em saúde foram realizadas, no segundo semestre de 2013, em escolas municipais de três distritos pertencentes a zona rural de Campos Sales, Ceará. São eles, os distrito de Monte Castelo, Barão de Aquiráz e Quixariúz, na Escola de Ensino Infantil e Fundamental Dr. Clóves Lopes dos Reis e em dois anexos da Escola de Ensino Fundamental e Médio de Campos Sales, respectivamente.

O foco das abordagens foi a juventude na faixa de escolaridade que geralmente contempla os adolescentes e pré-adolescentes, a partir da $5^{\circ}$ ano do ensino fundamental atingindo até os do ensino médio.

Realizaram-se palestras educativas aos jovens, que foram incentivos a compartilhar experiências como a sua primeira vez com o álcool, a sua percepção sobre a bebida e sua perspectiva de consumo para no futuro.

Antes da aplicação prática, foi solicitado à coordenação da escola o pedido de autorização para as palestras, sendo essas realizadas somente mediante assinatura dos coordenadores da instituição.

Os recursos audiovisuais foram constantemente explorados com o intuito de fundir realidades e experiências, aproximando os adolescentes da ideia abordada. Foram apresentados vídeos para apresentação do tema e usadas várias imagens para direcionamento dos argumentos.

$\mathrm{Na}$ primaira etapa, conteúdo da pelestra sugestionou a formulação processual do conceito de alcoolismo. À princípio, foi importante explanar a forma como o ácool age no organismo, qual o caminho percorrido por ele, como ocorre a absorção e a metabolização inicial.

Foi repassado para os adolescentes a explicação do efeito predominantemente depressor da droga no ao organismo, visão que não é focada pela mídia e propagandas, e embora explicitada na prática, não é uma visão muito otimista para os simpatizantes, já que a visão de socialização vendida pelo álcool não passa pela vinculação maciça de nada que lembre a depressão.

Ainda na fase da formulação em conjunto do conceito de alcoolismo, os jovens foram apresentados a motivos que geralmente levam muitos deles ao consumo precoce, tendo visto que isso não é alvo de reflexão por parte dos mesmos. $\mathrm{O}$ vício é que costuma forçar a autoavaliação, muitas vezes, apenas punitiva e melancólica, o que pode, ou não, ser o começo da mudança.

Os jovens tiveram noção da complexidade de fatores que podem agir de forma individal e específica durante a formulação da personalidade e que podem contribuir para que sejam criados conceitos distorcidos quanto ingestão da bebida, como por exemplo, o convívio com o consumo dentro de casa pelos próprios pais, que são naturalmente o maior exemplo para os filhos.

A seleção dos amigos, com base no consumo, foi exemplificada, e além desse motivo foram citados alguns fatores que levam muitas pessoas ao primeiro gole, como: a idéia da ajuda na paquera; as propagandas de bebida sempre vendendo em seus anúncios a idéia de amizade, felicidade, conquista de mulheres deslumbrantes; e problemas da vida que nos convidam a beber para que os esqueçamos, e não os resolvamos. Tudo isso contrastando com o fim trágico a que o consumidor pode estar destinado, assim como a determinação do destino de outras pessoas e de suas famílias. Por 
fim, a conceituação do problema passou pela explicação das fases do alcoolismo.

$\mathrm{Na}$ segunda etapa foram apresentados os efeitos que o consumo em excesso causa no indivíduo e na sociedade, começando pelo aumento nas chances de se envolver em acidentes de trânsito. A ingestão do álcool torna as pessoas inaptas à dirigir, já que o efeito deste dimnui a coordenação motora e os reflexos, o que prejudica o tempo de resposta e coloca em risco a integridade dos indivíduos no trânsito ${ }^{(4)}$. Foi indispensável falar-lhes sobre as várias formas com que o o consumo exagerado pode desgastar o indivíduo, levando-o a acidentes de trânsito; depressão e isolamento social; assacinatos; às doenças e complicações à saúde provocadas pelo uso crônico e até mesmo a morte.

As doenças relacionados ao abuso de álcocol mereceram uma abordagem mais detalhada, com foco especial na cirrose hepática, alterações comportamentais e físicas. Foi oportuno também falar sobre a carcterística social do álcool de funcionar como possibilidade para um mergulho mais profundo, dessa vez, no mundo das drogas ilícitas.

$\mathrm{Na}$ terceira etapa foi conveniente fazê-los refletir sobre qual a sua posição em relação aos alcoólatras, frequentemente menosprezados e/ou marginalizados pela sociedade. Os adolescentes tiveram a oportunidade de se auto-avaliar em relação ao álcool, deduzindo que o alcoolismo é algo que os circunda, os convida e os seduz. Eis a oportunidade de sugerir-lhes a reflexão sobre o preconceito com os bêbados das ruas, que são na verdade, pessoas que precisam de ajuda, o exemplo de ser, nos quais eles não podem se transformar.

Sequencialmente, para instigar a auto reflexão dos presentes, foi entregue um questionário contendo as perguntas abaixo, com o intenção de funcionar como um teste para medir o grau de dependência com o álcool ${ }^{(4)}$ :

1. Você fica ansioso para beber e planeja suas atividades em função disso?

2. Bebe com a mesma satisfação quando está só e quando está acompanhado?

3. Obtém da bebida um estímulo ou uma sensação especial?

4. Bebe para ajudar a descontrair, para dormir ou para enferentar problemas emocionais?

5. Reserva tempo e dinheiro especilmente para beber?

6. Muitas vezes acaba bebendo mais do que queria?

7. Parece capaz de beber mais do que as outras pessoas?

8. Às vezes, esquece-se de coisas que aconteceram qundo bebe?

$\mathrm{Na}$ quarta etapa, foi proposta uma dinâmica de grupo que com a missão de levantar informações sobre os possíveis desfechos negativos que o álcool já provocou na vida dos alunos e das pessoas próximas a eles. Os jovens foram convidados a se dispor em filas onde todos se encontravam em um mesmo nível, lado a lado, e de frente para a parede, que representou o limite para eles. Em seguida, foi avisado que não falassem nada (o silêncio os obrigaria a pensar), e que apenas reagissem às perguntas dando um passo à frente caso a resposta seja SIM, ou, permanecendo no lugar se a resposta for NÃO. À princípio, as perguntas falaram sobre questões mais sutis, como o primeiro gole. Depois foram instigados a lembrar de: pessoas que já adoeceram por conta do álcool, acidentes de pessoas conhecidas e até sobre mortes por conta da doença. 
Após a dinâmica, os jovens receberam um roteiro para uma breve avaliação de prendizagem da intervenção, a qual foram submetidos.

Este trabalho foi elaborado e foi desempenhado considerando os aspectos éticos inerentes a essa atividades, respeitando os indivíduos em estudo e não causando dano físico ou psicológico, tendo em mente o respeito ao ser humano em suas diferentes formas e complexidades.

\section{RESULTADOS}

Os resultados desse trabalho vão além dos números necessários à elaboração de dados sobre consumo abrangem o universo da permissividade quase que intuitiva ao consumo, algo contido na cultura da população estudada. Isso é notado em depoimentos espontâneos como o de uma das jovens que relatou: "Mas o vinho pode, o vinho é de Deus". Nesse momento o riso tomou conta da pequena turma. A associação feita pela menina, ligando o vinho da missa à idéia de permissividade, pelo fato da missa ser da "vontade de Deus", e que por isso seria uma justificativa plausível para a bebida dentro do universo dos valores individuais e expondo a fragilidade de se influenciar do ser humano.

Ainda que os adolescentes tenham se reconhecido nas situações expostas, foi causa de surpresa e exposição dos fatores que influenciam os jovens ao consumo, já que refletir sobre isso se mostrou ser algo raro, ficando em primeiro plano as experimentações sem questionamento lógico.

Quando se apresentou o adolescente como um ser em formação que tem a necessidade de fazer parte de um grupo, houve uma grande aceitação. Os exemplos se seguiram quando foi citado o fato de muitos jovens começarem a beber para se tornarem mais desinibidos nas paqueras. A mulher bonita, que parece ser vendida nas propagandas fez sucesso, e a compreensão dos alunos quanto às diferentes estratégias de marketing dos comerciais, foi animadora.

Os problemas gerados pelo consumo do álcool, tanto para o indivíduo como para a sociedade, causaram surpresa. Alguns dos jovens revelaram que nunca tinham parado para refletir no que essa droga lícita pode causar. Quando falou-se dos acidentes, os alunos logo citaram exemplos ligados ao álcool. O mesmo aconteceu quando mencionou-se do isolamento social, mudança de personalidade e violência, quase todos tinham histórias para contar.

A imagem do fígado cirrótico reproduzido pelo equipamento audiovisual causou espanto e repúdio. E essa era, realmente, a intenção. A etapa de exposição das comorbidades que acompanham o alcoolismo não foi negligenciada. Porém, o que parece ter chamado mais a atenção dos jovens, principalmente as meninas, foram os danos que o uso crônico do álcool pode causar na aparência física. Essa estratégia mostrou-se uma forma eficaz de levar informação ao meio jovem.

Ao fim, sugeriu-se aos participantes, em todas as palestras, a aplicação de um curto questionário com oito perguntas que os permitiria terem noção sobre a existência de dependência ao álcool e o seu grau de dependência.

Os resultados chamaram a atenção dos pesquiadores, uma vez que se tratava de uma zona rural de uma cidade do interior, onde as condições socioeconômicas estão longe das desejáveis. Do total de jovens, $13,54 \%$ afirmaram ficar ansiosos para beber e que planejam suas atividades em função disso; $21,29 \%$ disseram que bebem com a mesma satisfação quando estão sós e quando estão acompanhados; 24,51\% obtêm da bebida um estímulo ou uma sensação especial; 22,58\% 
afirmam que bebem para ajudar a descontrair, para dormir ou para enfrentar problemas emocionais; $9,67 \%$ reservam tempo e dinheiro especialmente para beber; $34,83 \%$ revelam que muitas vezes acabam bebendo mais do que queriam; $12,25 \%$ reconhecem que parecem beber mais do que as outras pessoas; 38,6\% confessam que, às vezes, esquece-se de coisas que aconteceram quando bebe. Chama a atenção a quantidade de pessoas que afirmam ter esquecido de acontecimentos quando bebeu, isso é um claro sinal do excesso de consumo. O percentual mais baixo, porém, não menos significativo, foi pessoas que reservam tempo e dinheiro especilmente para beber. A baixa renda da população parece ter influência, poucos do alunos em questão tem alguma fonte de renda regular, mas, ainda assim, quase $10 \%$ dos jovens têm esse hábito de reservar o pouco do que têm para beber.

Um percentual de 38,06\% respondeu de uma a três respostas SIM, e $20 \%$ a quatro ou mais respostas SIM. Uma resposta sim já é um indicativo de que a pessoa está dando mais importância ao álcool do que deveria, é um sinal de alerta, sendo necessário refletir sobre o seu padrão de consumo e começar a valorizar outras alternativas para a descontração. Quatro ou mais respostas sim, no entanto, indicam um grau de dependência alcoólica já instalado, onde é necessário procuar ajuda em organizações como os AA (Alcoólicos Anônimos) e/ou a profissionais como médico e psicólogo ${ }^{(4)}$.

Entre os que responderam ao menos uma resposta SIM: 23,33\% ficam ansiosos para beber e planejam suas atividades em função disso; 36,66\% bebem com a mesma satisfação quando estão sós ou acompanhados; 42,22\% obtêm da bebida um estímulo ou uma sensação especial; 38,88\% bebem para ajudar a descontrair, para dormir ou para enferentar problemas emocionais; $16,66 \%$ reservam tempo e dinheiro especilmente para beber; $60 \%$ acabam bebendo mais do que queriam; $21,11 \%$ parecem capazes de beber mais do que as outras pessoas, e; $65 \%$ afirmam que, às vezes, se esquecem de coisas que aconteceram quando bebem. Entre os que responderam ao menos um SIM, 63,55\% responderam de uma a três questões positivamente, e, 34,44\% disseram SIM a quatro ou mais perguntas.

A dinâmica da reflexão, última parte da palestra, provou o pensamento crítico e individual dos participantes, os colocou no universo dos prejuízos causados à sociedade pelo álcool. À princípio, eles não levaram tão a sério, mas no decorrer do tempo, logo viram o real sentido da dinâmica. Quando os adolescentes mudavam suas feições logo após as perguntas, percebia-se neles a desejada reflexão, e mais, a lamentação com a dependência dos outros.

Acredita-se que adquiriram mais discernimento e capacidade de escolha, algo, embora desejado, raro entre os jovens. Para finalizar, foi questionado sobre qual a perspectiva para seus futuros. De forma quase unânime, os alunos afirmaram não quererem para si o mesmo futuro de muitos de seus conhecidos.

\section{CONCLUSÃO}

A carência dos estudantes por estratégias mais carismáticas de ensino foi a primeira das várias conclusões que se pôde tirar. Perguntavam e ouviam como se estivessem com uma sede duradoura de conhecimento. Ficou claro que o conhecimento é um caminho de mão dupla, como sugere Rubens Alves, e não somente lançado aos alunos como muitas vezes acontece no processo de ensino.

A busca pela diversão "apoiada" pelo álcool é uma procura independente e livre da tristeza, supõem os jovens. Por isso, a surpresa 
quando lhes é exposta a associação direta entre o consumo crônico do álcool e a depressão que é uma das consequências desse uso, a ponto da opção pelo consumo soar como natural.

Os motivos que levam os adolescentes ao vício não costumam ser alvo de reflexão por eles, em especial as estratégias de marketing das propagandas de bebida, que acabam sendo vistas como simpáticas, e, portanto, inofensivas. Isso revela a inexistência efetiva de estratégias de conscientização nas escolas e a possível falência educacional do papel da família nesse aspecto, sendo, em determinadas situações, até indutiva ao consumo, algo explicitado por exemplificações verbais dos estudantes.

Com a aplicação do questionário, concluise, que é relevante a porcentagem de adolescentes que demonstram esquecer as lembranças do dia anterior devido a embriaguez, assim como a dos de jovens que reservam tempo e dinheiro para beber, considerando a escassez das fontes de renda na população estudada, além do fato da tendência ao aumento do consumo, se não paralela a melhoria na educação, não ser favorável à melhoria no perfil de consumo. É alarmante o número de jovens que já apresentam certo grau de dependência, o que contribui para que o resultado dessa análise situacional revele uma necessidade urgente de intervenção da família, escola, Organizações Não Governamentais, ações locais e de políticas públicas.

\section{REFERÊNCIAS}

1. World Health Organization. Strategies to reduce the harmful use of alcohol. Geneva; 2008. . Disponível em: http://apps.who.int/gb/ebwha/pdf files/A61/A61 1 3-en.pdf

2. MALTA, D. C. et al. O consumo de bebidas alcoólicas, a condução de veículos, uma balança de lei seca, Brasil 2007-2014. Rev. Saúde Pública [online]. 2014; 48(4): 692-966. ISSN 0034-8910.
http://dx.doi.org/10.1590/S0034-

8910.2014048005633 .

3. ALAVARSE, G.M.A.; CARVALHO, M.D.B. Álcool e adolescência: o perfil de consumidores de um município do norte do Paraná. Esc Anna Nery R Enferm. 2006 ; 10(3): 408 - 16.

4. AZEVEDO, R.B. Drogas: Um Guia para a Família. São Bernardo do Campo: Grupo Saúde e Vida. 2004

5. DUAILIBI, S; LARANJEIRA, R. Políticas públicas relacionadas às bebidas alcoólicas. Rev. Saúde Pública [online]. 2007; 41(5): 839-848. ISSN 0034-8910. http://dx.doi.org/10.1590/S0034$\underline{89102007000500019}$.

6. MARTINS, O. Efeito do consumo de bebidas alcoólicas no organismo: uma revisão. Revista Eletrônica de Educação e Ciência (REEC). 2013; 3(2): 7-10. ISSN 2237-3462

7. WOLFARTH, S.P. As consequências do álcool nos adolescentes. 2013. Acesso em 27 de Novembro de 2013, disponível em Valorização da Vida:

http://www.valorizacaodavida.com.br/home/textose-mensagens/textos-e-mensagens/as-

consequeencias-do-alcool-nos-adolescentes-e-nosjovens

8. RODRIGUES, A.P, OLIVEIRA, A.S ZALESKI, E.G.F, ARANTES,S.L. Avaliação do nível de propensão para o desenvolvimento do alcoolismo entre estudantes do curso de graduação em enfermagem da Universidade Católica Dom Bosco.SMAD, Rev. Eletrônica Saúde Mental Álcool Drog. (Ed. port.)[online]. 2007; 3(1): 1-10. ISSN 1806-6976.

9. OMS. Organização Mundial de Saúde - Informe mundial de saúde, Genebra; 2002.

10. BRASIL. Ministério da Saúde. Política Nacional de Atuação Integral à Saúde do Homem (Princípios e Diretrizes). Brasília, 2009.

11. BALDISSERA, A. Pesquisa-ação: Uma metodologia do "conhecer" e do "agir" coletivo. Sociedade em Debate. 2001; 7(2): 5-25.

12. MARCONI, M.A; LAKATOS, E.M Fundamentos da Metodologia Científica. $7^{\mathrm{a}}$ ed. São Paulo: Atlas, 2010 